\title{
Passive Seismic Deployments from the Lützow-Holm Bay to Inland Plateau of East Antarctica: The Japanese IPY Contribution to Structure and Seismicity
}

\author{
Masaki Kanao ${ }^{1}$, Akira Yamada ${ }^{2}$, Genti Toyokuni ${ }^{3}$ \\ ${ }^{1}$ National Institute of Polar Research, Tokyo, Japan \\ ${ }^{2}$ Geodynamics Research Center, Ehime University, Matsuyama, Japan \\ ${ }^{3}$ Research Center for Prediction of Earthquakes and Volcanic Eruptions, Graduate School of Science, \\ Tohoku University, Sendai, Japan \\ Email: kanao@nipr.ac.jp,yamada@sci.ehime-u.ac.jp, toyokuni@aob.gp.tohoku.ac.jp
}

Received April 23, 2013; revised May 26, 2013; accepted June 24, 2013

Copyright (C) 2013 Masaki Kanao et al. This is an open access article distributed under the Creative Commons Attribution License, which permits unrestricted use, distribution, and reproduction in any medium, provided the original work is properly cited.

\begin{abstract}
Deployments of seismic stations in Antarctica are an ambitious project to improve the spatial resolution of the Antarctic Plate and surrounding regions. Several international programs had been conducted in wide area of the Antarctic continent during the International Polar Year (IPY 2007-2008). The "Antarctica's GAmburtsev Province (AGAP)", the "GAmburtsev Mountain SEISmic experiment (GAMSEIS)" as a part of AGAP, and the "Polar Earth Observing Network (POLENET)" were major contributions to the IPY. The AGAP/GAMSEIS was an internationally coordinated deployments of more than few tens of broadband seismographs over the wide area of East Antarctica. Detailed information on crustal thickness and mantle structure provides key constraints on an origin of the Gamburtsev Mountains; and more broad structure and evolution of the East Antarctic craton and sub-glacial environment. From POLENET data obtained, local and regional signals associated with ice movements were recorded together with a significant number of teleseismic events. Moreover, seismic deployments have been carried out in the Lützow-Holm Bay (LHB), East Antarctica, by Japanese activities. The recorded teleseismic and local events are of sufficient quality to image the structure and dynamics of the crust and mantle, such as the studies by receiver functions suggesting a heterogeneous upper mantle. In addition to studies on the shallow part of the Earth, we place emphasis on these seismic deployments' ability to image the Earth's deep interior, as viewed from Antarctica, as a large aperture array in the southern high latitude.
\end{abstract}

Keywords: Passive Seismic Deployments; Lützow-Holm Bay; East Antarctica; Mantle Structure; Earth’s Deep Interiors

\section{Introduction}

Existing permanent stations of the Federation of Digital Seismographic Network (FDSN) allow resolution of the structure beneath Antarctica at a horizontal scale of $\sim 1000 \mathrm{~km}$, which is sufficient to detect fundamental differences in the lithosphere between East and West Antarctica, but not to clearly define the structure within each sector. Detection of seismicity around the Antarctic is limited by the sparse station distribution and the detection level for local earthquakes remains inadequate for full evaluation of tectonic activity [1]. A strategy of attaining a sufficient density of seismic stations on the continent will allow for optimal ray path coverage across Antarctica and improvement of the resolution of seismic tomography [2]. In addition to the lithospheric studies, the teleseismic data have advantages in investigating a deeper part of Earth's interior such as lower mantle, D" layers, the core-mantle boundary (CMB) as well as the inner core as they are effectively a large span array located in Antarctica.

The International Polar Year (IPY 2007-2008) provided an excellent opportunity to make significant advances in seismic deployments to achieve the science targets. Following the successful "TransAntarctic Mountain SEISmic experiment (TAMSEIS; [3]) deployment" in 2000-2002, several big geo-science projects were conducted to study the interior of Antarctic continent and surrounding region (Figure 1). The original idea of passive seismic deployments had been modified according to the logistical and financial concerns, but remained 


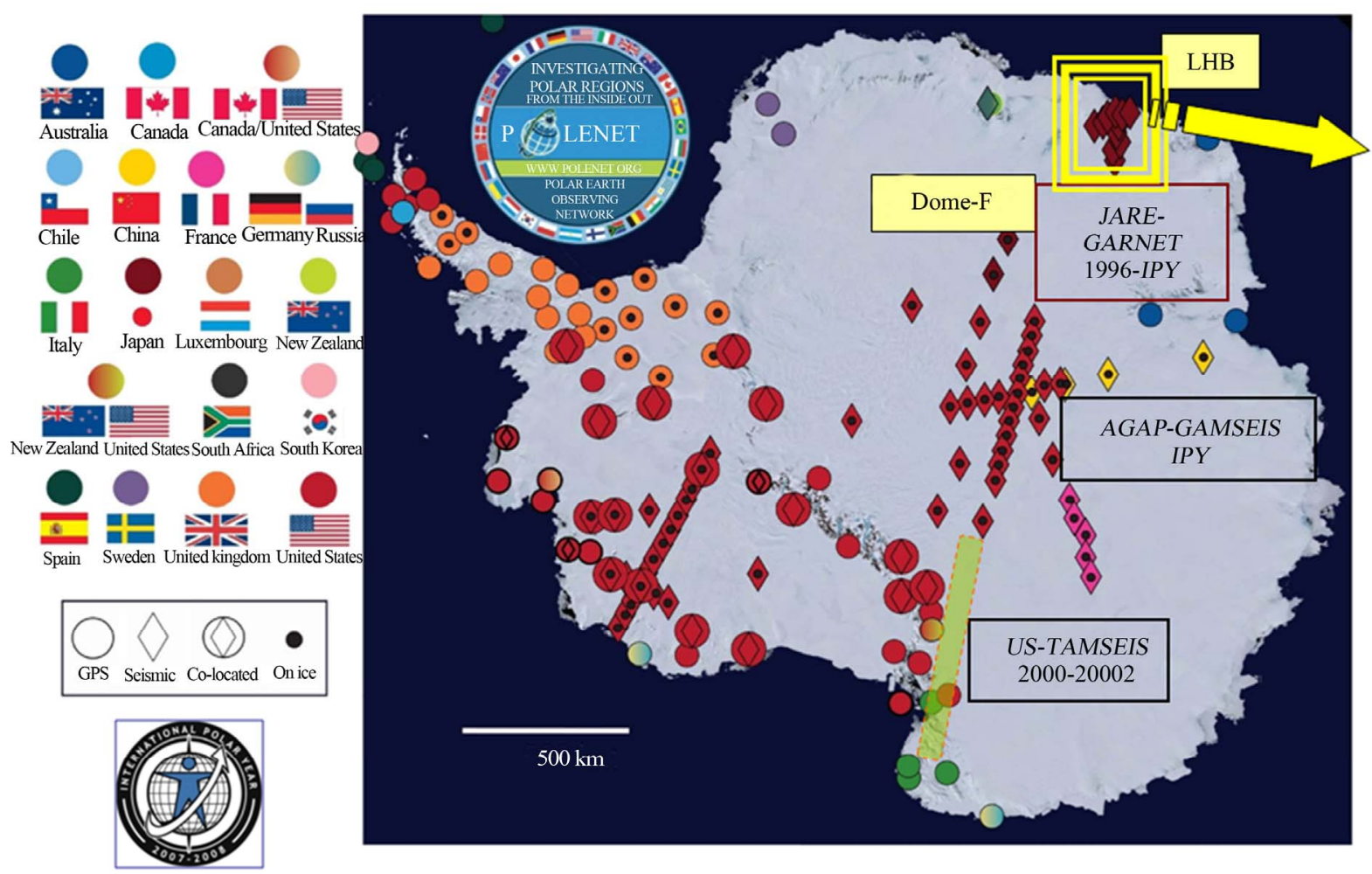

Figure 1. Distribution of the seismic (squares) and geophysical stations (GPS; circles) deployed by major projects at the IPY. The project names are labeled as; JARE-GARNET, AGAP-GAMSEIS and US-TAMSEIS, respectively. All stations in the Antarctic continent had been contributed to the POLENET program. LHB: the Lützow-Holm Bay; Dome-F: Dome-F station.

by sincere supports from many nations involved in the Antarctic research. The resultant broadband seismic stations in Antarctica were put together for initiating the major international programs [4] during the IPY.

The "Antarctica's GAmburtsev Province (AGAP; IPY \#147)", the "GAmburtsev Mountain SEISmic experiment (GAMSEIS; http://epsc.wustl.edu/seismology/GAMSEIS/)" as a part of AGAP, and the "Polar Earth Observing Network (POLENET; http://www.polenet.org, IPY \#185)" were the largest contributions in establishing a seismic network in Antarctica at the IPY. Targeting the vast central region of East Antarctica, the AGAP/GAMSEIS was an internationally coordinated deployment of few tens of broadband seismographs over the crest of the Gambursev Subglacial Mountains (GSM, around Dome-A), Dome-C and Dome-F area [5]. The investigations provided detailed information on crustal thickness and mantle structure and provide key constraints on the origin of the GSM [6], and more broadly on the structure and evolution of the East Antarctic craton and underlying upper mantle [7, 8].

Moreover, the seismic deployments between Eastern Dronning Maud Land and Enderby Land area, by the Japanese Antarctic Research Expedition (JARE; [9]) significantly contributed as a part of both POLENET and
AGAP/GAMSEIS. From the data obtained, local and regional seismic signals associated with ice movements, oceanic loading and local meteorological variations were recorded in addition to a significant number of teleseismic events. In this paper, field operations during the IPY mainly by JARE activities from the Lützow-Holm Bay (LHB) to the inland plateau area are summarized and the significance to study the Earth's interior as well as the local seismicity is demonstrated. In addition to reviewing the seismological approaches for the shallow part of the Earth, we also put weights on the Earth's deep interiors, as viewed from Antarctic continent as a large aperture of seismic arrays in southern high latitude.

\section{Passive Deployments over the East Antarctica}

Targeting the underlying structure, dynamics and evolution of the broader part of East Antarctica, the AGAP was an internationally coordinated program including sub-groups of air-borne geophysics, seismics and icecore drilling [4]. Multi-national collaboration both for science investigation and field operational logistics by many nations from USA, Japan, China, France, Italy and Australia was a significant factor in the success of the project. Among the whole AGAP, a sub-group named 
GAMSEIS deployed few tens of broadband seismographs over a wide area of the continental ice sheet from the GSM, Lake Vostok, and in the vicinity of Dome-F (Figure 1). Although we do not mention the details in logistics here, a significant number of flights have been conducted by Twin-Otter aircraft in order to install the stations on ice sheet.

The seismic instrumentation utilized for GAMSEIS and POLENET were provided by the Program for Array Seismic Studies of the Continental Lithosphere (PASSCAL) of the Incorporated Research Institutions for Seismology (IRIS). A review of the field operations at remote sites in polar region at IPY, both for Antarctica and Greenland, are summarized by [10]. The PASSCAL polar instruments were developed with input from the community of Antarctic seismologists and the main specifications are as follows [11,12]. Seismometer; Guralp CMG-3T in a special configuration to operate at $-55^{\circ} \mathrm{C}$, Datalogger; Quanterra Q-330 with flash memory (operates to $-55^{\circ} \mathrm{C}$ ), Enclosures; insulated vacuum keep at $15^{\circ} \mathrm{C}$ above ambient without additional heating, Solar panels and AGM batteries for summer power, Lithium batteries for winter power, and these instruments were optimized for ease of deployment from Twin-Otter aircraft.

In addition to the PASSCAL observation system, the originally coordinated systems were developed by Japan (at Dome-F and the vicinity stations), and also by the other research groups of China and France. Regarding the Japanese instrument system, the same sensor and data-logger as used by US/PASSCAL were utilized, but the electric power supply system and enclosures were developed independently with technical advice from PASSCAL staff. A continuous data were recorded in the MiniSEED format, a commonly accepted international standard, to ease analysis. Logistical and staff support were provided by the US researchers and staff at AGAP camp in the installation of the Japanese stations around Dome-F. Buried beneath the thick ice sheet, the GSM was characterized by peak elevations of more than $\sim 3000$ $\mathrm{m}$ above sea level [13]. The new data from GAMSEIS has also allowed for more detailed investigation of the crustal structure beneath the GSM and the surrounding regions [6].

\section{Passive Deployments from LHB to Inland Plateau}

Outside the AGAP/GAMSEIS deployed area along the continental margins of East Antarctica, several seismic stations have been deployed in LHB (Figure 2). The observations have been carried out initially from 1996 until present and serve as the data contribution to POLENET and FDSN. The stations were established on the outcrops and ice sheet around the continental margins of LHB. A significant number of teleseismic events, local earthquakes, and ice-related events within close to the stations have been recorded. During the IPY, seven stations were continuously operated at LHB. The observation systems consisted of a portable broadband seismometer and a data-recorder (Japanese original), combined with AGM batteries and solar panels. Guralp Systems CMG-40T seismometers were mainly utilized.

Detailed information for the local array stations in LHB and operational information are available from the web-site of NIPR (http://polaris.nipr.ac.jp/ pseis/garnet/). The data of LHB array stations were initially stored and accessible to cooperative researchers through the data library server of NIPR (POLARIS). After a defined period, the data are made available to world data centers of seismology, such as the Data Management System (DMS) of IRIS. The global data centers provide data to seismologists studying the polar regions, the Standing Committee on Antarctic Data Management (SCADM) under the Scientific Committee on Antarctic Research (SCAR), as well as the Antarctic Master Directory (AMD) in the Global Change Master Directory (GCMD) of NASA.

During the IPY, broadband seismic deployments in LHB were conducted under the umbrella of endorsed JARE project. By combining with the other big IPY projects such as AGAP/GAMSEIS, moreover, the deployments in LHB could provide constraints on the origin of GSM in terms of understanding the broader structure of Antarctic Pre-Cambrian craton, underlying upper mantle and the sub-glacial environment. Detection of seismic signals from basal sliding of the ice sheet and ice streams would be expected from the future study, as well as the detection of outburst floods from the sub-glacial lakes within the continent.

\section{Retrieved Data and Major Scientific Targets}

During the IPY, a significant number of teleseismic events, as well as many local and regional signals were recorded at the AGAP/GAMSEIS and POELNET stations. Teleseismic data obtained provide detail information on crustal thickness and mantle temperatures beneath Antarctica through regional receiver function and tomography. Data collected by AGAP/GAMSEIS are capable of providing key constraints on the origin of GSM as a crustal root associated with ancient orogenic events [6], and more broadly on the structure and evolution of the entire East Antarctic craton [7,8,14]. A map of crustal thickness beneath GSM indicates large values over $55 \mathrm{~km}$, which imply an ancient mountain range may have been supported by thick, buoyant crust [7]. These new images of the crust and upper mantle in the middle part of East Antarctica aid in understanding 

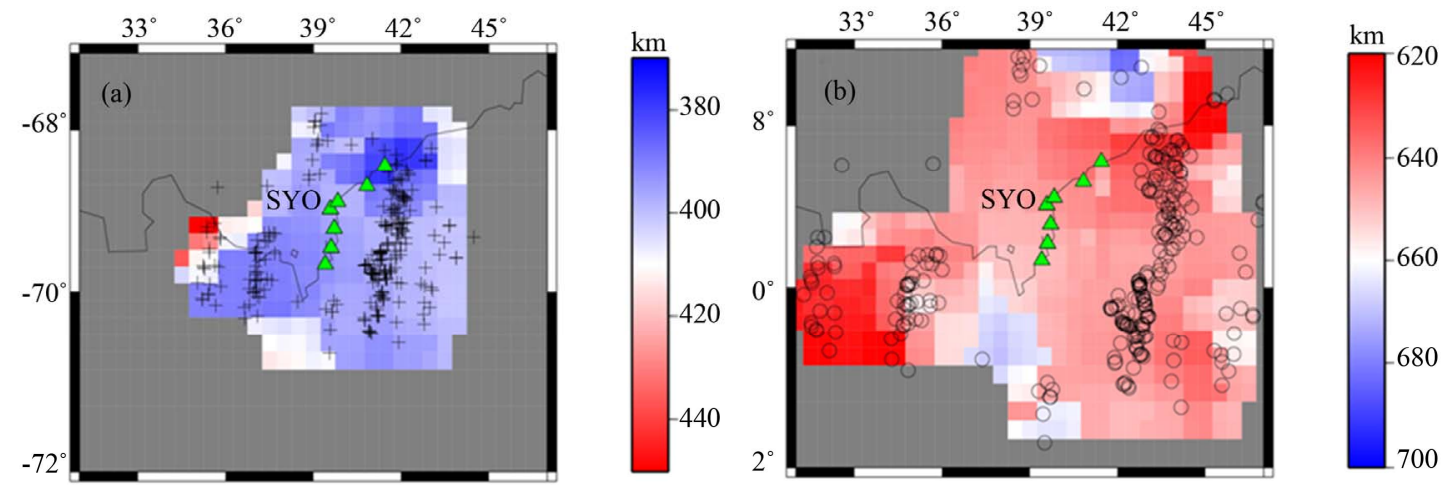

Figure 2. Distribution of P-S conversion depth points for $410 \mathrm{~km}$ (a) and $660 \mathrm{~km}$ (b) discontinuities, respectively. Location of the conversion depth points was obtained by combining seismic station positions in LHB and hypocenters of the utilized teleseismic events. Topographic depth variations of the upper mantle discontinuities are presented by the color contours (modified after [9]).

the evolution of Gondwana super-continent during Earth's history.

Several kinds of natural seismic signals connected to the atmosphere-ocean - cryosphere system can be detected in polar regions. The movement of ice is capable of causing small magnitude earthquakes, generally labeled "ice-quakes" (or "ice-shocks") for their relationship to glacial dynamics $[15,16]$. Such kinds of cryoseismic sources are considered to have been composed of the movement of ice sheets, sea-ice, oceanic tide-cracks, oceanic gravity waves, icebergs and the calving fronts of ice caps. Cryoseismic sources are likely to be influenced by surface environmental conditions, and their temporal variations provide indirect evidence of climate change appeared in polar regions.

In addition to ice motion signals, almost all seismic stations deployed on Earth's surface record ubiquitous signals at periods between 4 and $25 \mathrm{~s}$, commonly referred to as "microseisms". Microseisms are considered to be dominated by Rayleigh waves that arise from gravity waves in the ocean that are forced by surface winds. The period ranges of microseisms are dictated by the physics of gravity wave generation, and are constrained by the speed and extent of Earth's surface winds [17,18]. On a global scale, microseism amplitudes are generally highest during local winter, because nearby oceans are stormier in winter than in summer [19]. In contrast, we observe the opposite in polar regions [20]. The evidence can be explained by the sea-ice extent impeding both the direct ocean-to-continent coupling and the coastal reflection. Microseism studies of Antarctica using IPY data have recently been undertaken with fruitful results $[16,20]$.

\section{Velocity Discontinuities in the Upper Mantle}

Characteristic seismic evidence in terms of structure and dynamics of LHB was obtained by JARE local deploy- ments. Teleseismic data have sufficient quality for usage of various analyses to clarify the heterogeneous features of the crust and upper mantle, tectonic evolution of the region, as well as deep interiors $[21,22]$. Shear wave velocity models were inverted by fitting synthetic receiver functions to the observed data in short-period ranges. The obtained model investigated from azimuthal variations of the receiver functions represents a slightly dipping crust mantle boundary toward the coast. Moreover, a gradual thickened structure of the crust in LHB was identified from the north toward the south [23]. Variations in crustal thickness along the coast may reflect the tectonic history involving super-continent evolution, with increasing metamorphic grade in crystalline crust towards the southern part of LHB.

Along with the crustal studies, long period receiver functions (after $0.2 \mathrm{~Hz}$ low-pass filter) demonstrate the depth variations in mantle discontinuities for both 410 $\mathrm{km}$ and $660 \mathrm{~km}$ in LHB, respectively [9]. The azimuthal heterogeneities were also identified in both $410 \mathrm{~km}$ and $660 \mathrm{~km}$ discontinuities in the two azimuth ranges of $20^{\circ}$ $50^{\circ}$ and $200^{\circ}-260^{\circ}$. The two back azimuth groups are almost parallel with the coast of LHB and may indicate the relationship with the break-up process of Gondwana super-continent. The evidence of break-up supported by other studies from teleseismic shear wave anisotropy and reflection imaging by active source surveys [24].

Local seismicity around the LHB was reported by [16] (Figure 3). The seventeen events, except for the 1996. $\mathrm{Sep} . \mathrm{Mb}=4.6$ earthquake in the southern part of Indian Ocean, had been determined by local stations at LHB. The all hypocenters are identified to be located along the coast, otherwise the northern edge of the continental shelf. Several events may be large ice-quakes associated with sea-ice dynamics around the bay or in the southern ocean. Despite the development of local networks in the last two decades, we can hardly distinguish a difference 


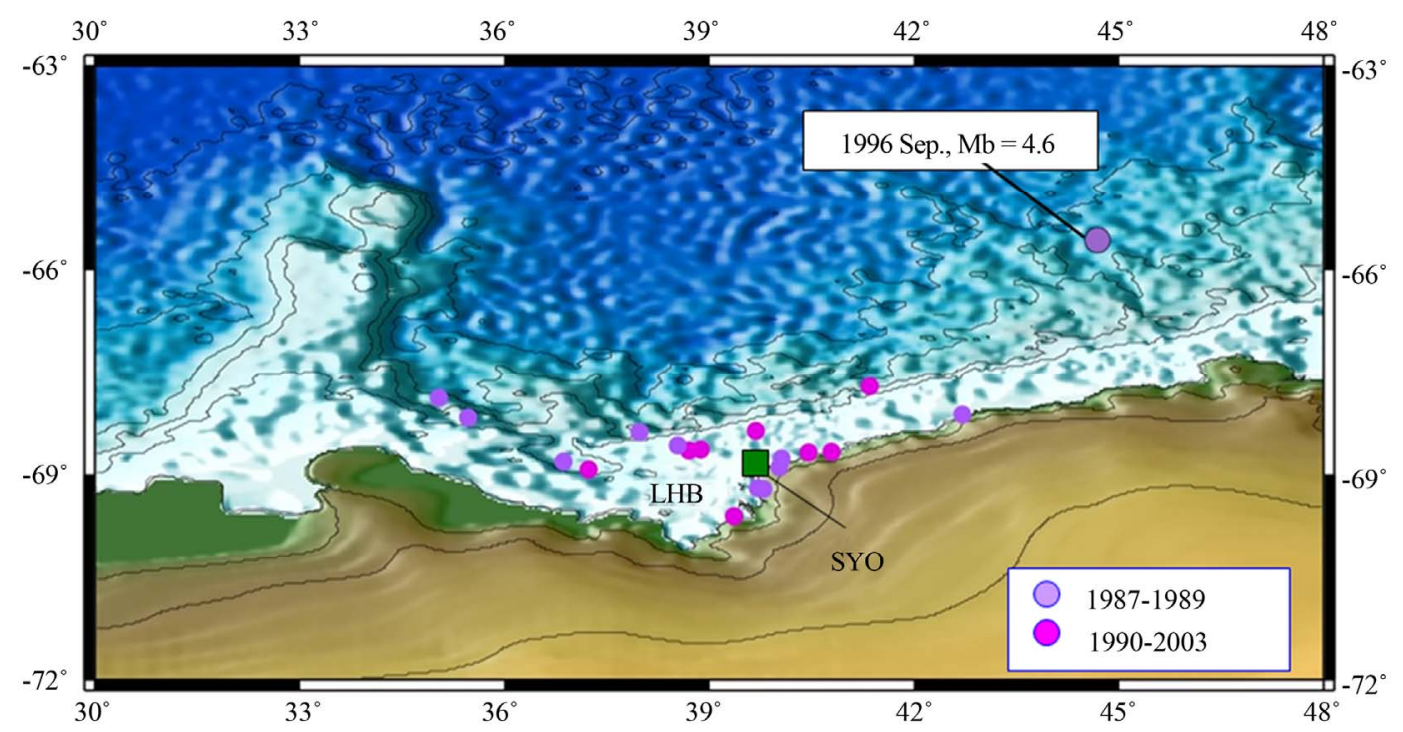

Figure 3. Local seismicity around the LHB region from 1987 to 2003 (modified after [16]). These events, except for the 1996. Sep. $\mathrm{Mb}=4.6$ earthquake in the Indian Ocean, had been determined by the local seismic network deployed at the LHB.

between waveforms by local tectonic earthquakes and those of ice-related phenomena. The ice-related signals can provide unique information for local impact on polar region involving global climate change.

\section{Study on Global Scale Structure}

In addition to the bedrock topography, crust and upper mantle that underlie the Antarctic ice sheet, the teleseismic data obtained by the AGAP/GAMSEIS, POLENET and JARE have a great advantage on heterogeneous structure and dynamics of the deep part of Earth's interior. The target depth areas are, for instance, the lowermost layer of the mantle ( $\mathrm{D}^{\prime \prime}$ region) and in the coremantle boundary (CMB) [21], together with the inner core [25]. The heterogeneous and anisotropic structure of these depth ranges could be investigated by using the teleseismic data retrieved at both polar regions by these studies, as a large aperture array located in the southern high latitude. Seismic data from inland Antarctica is expected to bring images of the Earth's deep interiors with enhanced resolution due to the high signal-to-noise ratio and wide extent of this region, as well as rarity of their sampling PKIKP paths along the rotation axis of the Earth as mentioned by [25].

By using the observed teleseismic waveforms detected by GAMSEIS and POLENET, the synthetic seismograms calculated by spherical 2.5-D finite-difference methods were compared to identify the lateral heterogeneity in realistic Earth's structure [26]. The source location used for the analysis is the Fiji earthquake. Compared waveforms in the vertical components between synthetic and observed are in Figure 4, which represent the good agreement of their waveforms. Although it is required to improve the more realistic structural model a more detailed seismic velocity model will ultimately be required, the agreement in the compared waveforms indicated potential of the spherical 2.5-D finite-difference model as a tool to reveal the deep inner structure of the Earth. The seismic station distribution by of GAMSEIS and POLENET, moreover, was found to be a sufficient number to fulfill the special spatial and back-azimuth coverage over the globe in the requirements for global wave-field modeling.

\section{Conclusion}

The IPY 2007-2008 provided an excellent opportunity to make significant progresses in geophysical networks of both polar regions. These advances serve as a crucial improvement on the permanent global network of FDSN and such projects as POLENET and other geo-science bodies and communities. Accumulated high quality data in Antarctica from POLENET, AGAP/GAMSEIS and JARE/LHB could be efficiently utilized to clarify the dynamic seismicity and heterogeneous structure of the Earth, particularly around the East Antarctica. Seismic deployments could efficiently study the crust and upper mantle, as well as the Earth's deep interior, including features such as the CMB and the lowermost mantle layer (the D" region). These studies also provide significant insight into the characteristics of seismicity associated with global environmental change. From the data obtained at IPY, local and regional seismic signals associated with ice sheet movement and meteorological variations were recorded. The detection of these signals from the phenomenon at the base of the ice sheet, such as outburst floods from sub-glacial lakes are expected from 

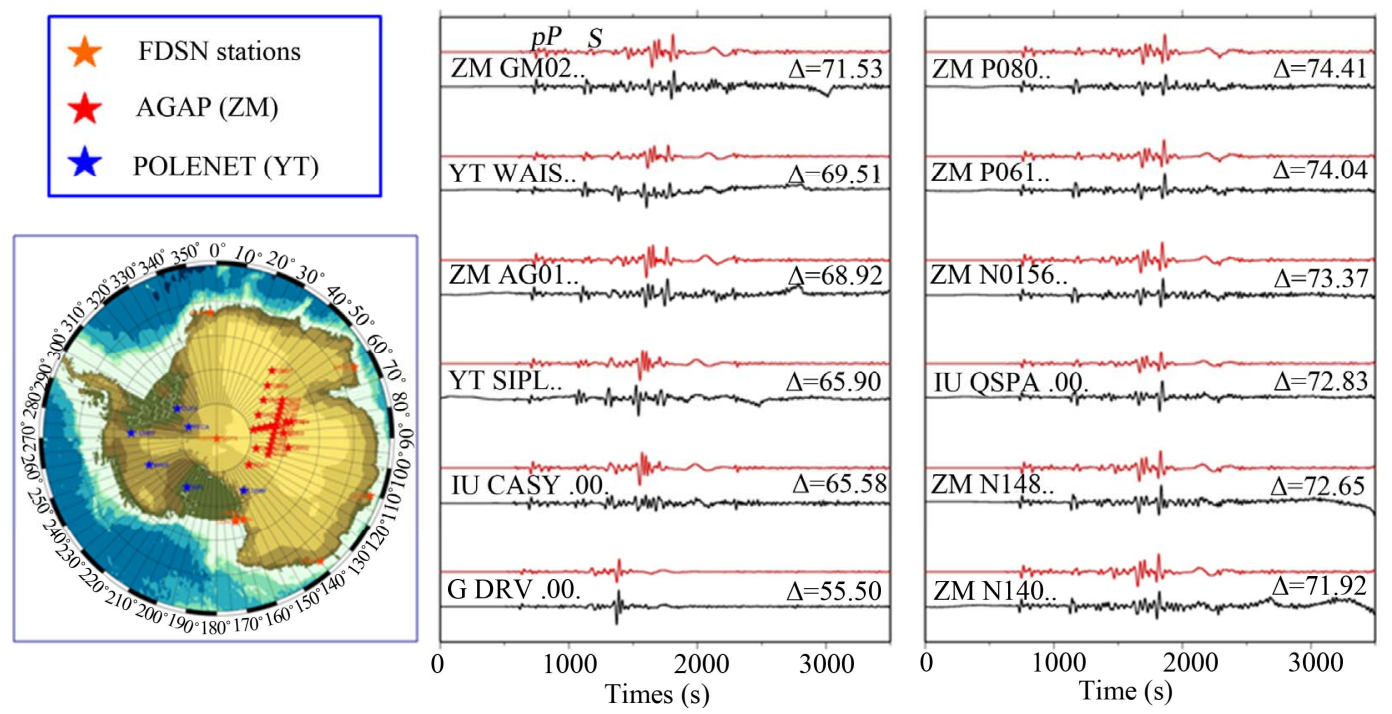

Figure 4. (Right) Seismic stations in Antarctica used for comparison between synthetic and observed seismograms. FDSN stations (orange), AGAP-GAMSEIS (red) and POLENET in West Antarctica (blue), respectively. (Left) Comparison of the vertical components of the Fiji teleseismic event, between synthetic waveforms by the spherical 2.5-D finite-difference method (red lines) and the observed waveforms (black broken lines) for several stations in Antarctica. The IRIS network and station code is represented at left side of each trace. Arrival times correspond to $\mathrm{pP}$ and $\mathrm{S}$ phases are raveled in the first waveform trace (ZM GM02) (modified after [26]).

detailed analyses. In addition to conventional seismological approaches for the shallow part of the Earth, we place significant emphasis on these arrays' ability to image the Earth's deep interior, as viewed from Antarctica, as a large aperture array in the southern high latitude.

\section{Acknowledgements}

The authors would like to express our special appreciation to the many collaborators in the IPY projects for AGAP (Prof. R. Bell and Dr. M. Studinger of LamontDoherty Earth Observatory of Columbia University and others), GAMSEIS (Profs. D. A. Wiens of Washington University in St. Louis and A. A. Nyblade of Pennsylvania State University, and others) and POLENET (Prof. T. Wilson and Dr. S. Konfal of the Ohio State University and others). We would like to express our sincere appreciation of our many collaborators in the Japanese Antarctic Research Expeditions (JARE; Prof. Kazuyuki Shiraishi, Director-in-General of NIPR and others). They would like to express their sincere thankfulness for Prof. F. Davey of the Institute of Geological and Nuclear Sciences Ltd, New Zealand, and Prof. A. K. Cooper of the Department of Geological and Environmental Sciences, Stanford University, for their critical reviews and useful comments under preparation of the manuscript.

\section{REFERENCES}

[1] A. M. Reading, "On Seismic Strain-Release within the Antarctic Plate,” In: D. K. Futter, et al., Eds., Antarctica: Con- tributions to Global Earth Sciences, Springer-Verlag, New York, 2006, pp. 351-356.

[2] M. H. Ritzwoller, N. M. Shapino, A. L. Levshin and G. M. Leahy, "Crustal and Upper Mantle Structure Beneath Antarctica and Surrounding Oceans," Journal of Geophysical Research, Vol. 106, No. 12, 2001, pp. 30645 30670. doi:10.1029/2001JB000179

[3] D. A. Wiens, S. Anandakrishnan, J. P. Winberry and M. A. King, "Simultaneous Teleseismic and Geodetic Observations of the Stick-Slip Motion of an Antarctic Ice Stream," Nature, Vol. 453, No. 7196, 2008, pp. 770-774. doi:10.1038/nature06990

[4] T. Wilson and R. Bell, "Earth Structure and Geodynamics at the Poles," Understanding Earth's Polar Challenges: International Polar Year 2007-2008, 2011, pp. 273-292.

[5] D. A. Wiens, "Broadband Seismology in Antarctica: Recent Progress and Plans for the International Polar Year," Proc. Inter. Symp.-Asian Collaboration in IPY 20072008, Tokyo, 2007, pp. 21-24.

[6] S. E. Hansen, A. A. Nyblade, D. S. Heeszel, D. A. Wiens, P. J. Shore and M. Kanao, "Crustal Structure of the Gamburtsev Mountains, East Antarctica, from S-Wave Receiver Functions and Rayleigh Wave Phase Velocities," Earth and Planetary Science Letters, Vol. 300, No. 3-4, 2010, pp. 395-401. doi:10.1016/j.eps1.2010.10.022

[7] D. S. Heeszel, D. A. Wiens, A. A. Nyblade, S. E. Hansen, M. Kanao, M. An and Y. Zhao, "Rayleigh Wave Constraints on the Structure and Tectonic History of the Gamburtsev Subglacial Mountains, East Antarctica," Journal of Geophysical Research, Vol. 118, No. 5, 2013, pp. 1-16. doi:10.1002/jgrb.50171

[8] A. J. Lloyd, A. A. Nyblade, D. A. Wiens, P. J. Shore, M. Kanao, S. E. Hansen and D. Zhao, "Upper Mantle Seis- 
mic Structure beneath the East Antarctic Shield from Body Wave Tomography: Implications for the Origin of the Gamburtsev Subglacial Mountains," Geochemistry, Geophysics, Geosystems, Vol. 14, No. 4, 2013, pp. 902920. doi:10.1002/ggge. 20098

[9] M. Kanao, Y. Usui, T. Inoue and A. Yamada, "Broadband Seismic Deployments for Imaging the Upper Mantle Structure in the Lützow-Holm Bay Region, East Antarctica," Geophysical Journal International, Vol. 2011, 2011, pp. 1-15. doi: $10.1155 / 2011 / 272646$

[10] K. Anderson and T. Parker, "Polar Operations," IRIS 2009 Annual Report-Twenty Five Years of IRIS, 2009, pp. 26-27.

[11] K. Anderson, B. Beudoin and T. Parker, "IRIS/PASSCAL Polar Power/Comms," MRI Year 1 Midseaon Report, 2007, $14 \mathrm{p}$.

[12] D. A. Wiens, “Autonomous Polar Observing Systems (APOS) Workshop Report," The National Sscience Fundation Supported Workshop, Maryland, 2011.

[13] R. E. Bell, F. Ferraccioli, T. T. Creyts, D. Braaten, H. Corr, I. Das, D. Damaske, N. Frearson, T. Jordan, K. Rose, M. Studinger and M. Wolovick, "Widespread Persistent Thickening of the East Antarctic Ice Sheet by Freezing from the Base," Science Xpress Report, 2011.

[14] M. An, D. A. Wiens, Y. Zhao, M. Feng, A. Nyblade, M. Kanao, Y. Li, A. Maggi and J.-J. Lévêque, "3D Lithosphere Model of the Antarctic Plate from Surface Wave Observations," Journal of Geophysical Research, 2013, in Press.

[15] S. Anandakrishnan, D. E. Voigt, R. B. Alley and M. A. King, "Ice Stream D Flow Speed Is Strongly Modulated by the Tide Beneath the Ross Ice Shelf," Geophysical Research Letters, Vol. 30, No. 7, 2003. doi:10.1029/2002GL016329

[16] M. Kanao, A. Maggi, Y. Ishihara, M.-Y. Yamamoto, K. Nawa, A. Yamada, T. Wilson, T. Himeno, G. Toyokuni, S. Tsuboi, Y. Tono and K. Anderson, "Interaction on Seismic Waves between Atmosphere-Ocean-Cryosphere and Geosphere in Polar Region," In: M. Kanao, et al., Eds., Seismic Waves-Research and Analysis, Rijeka, Croatia, InTech. Publisher, 2012, pp. 1-20. doi: $10.5772 / 1400$

[17] R. Aster, "Studying Earth's Ocean Wave Climate Using Microseisms," IRIS Annual Report, 2009, pp. 8-9.

[18] P. D. Bromirski, "Earth Vibrations," Science, Vol. 324,
No. 5930, 2009, pp. 1026-1027.

[19] E. Stutzmann, M. Schimmel, G. Patau and A. Maggi, "Global Climate Imprint on Seismic Noise," Geochemistry, Geophysics, Geosystems, Vol. 10, No. 11, 2009, Article ID: Q11004. doi:10.1029/2009GC002619

[20] M. Grob, A. Maggi and E. Stutzmann, "Observations of the Seasonality of the Antarctic Microseismic Signal, and Its Association to Sea Ice Variability," Geophysical Research Letters, Vol. 38, No. 11, 2011, Article ID: L11302. doi:10.1029/2011GL047525

[21] Y. Usui, Y. Hiramatsu, M. Furumoto and M. Kanao, "Evidence of Seismic Anisotropy and a Lower Temperature Condition in the D" Layer Beneath Pacific Antarctic Ridge in the Antarctic Ocean," Physics of the Earth and Planetary Interiors, Vol. 167, No. 3-4, 2008, pp. 205-216. doi:10.1016/j.pepi.2008.04.006

[22] M. Kanao, "Variations in the Crust Structure of the LüzowHolm Bay region, East Antarctica Using Shear Wave Velocity," Tectonophysics, Vol. 270, No. 1-2, 1997, pp. 43-72. doi:10.1016/S0040-1951(96)00207-7

[23] Y. Usui, M. Kanao and A. Kubo, "Upper Mantle Anisotropy from Teleseismic SKS Splitting Beneath Luutzow-Holm Bay Region, East Antarctica," In: A. K. Cooper, P. Barrett, H. Stagg, et al., Eds., Antarctica: A Keystone in a Changing World, US Geological Survey and The National Academies, 2007, SGS OF-2007-1047, Short Research Paper 013.

[24] M. Kanao, A. Fujiwara, H. Miyamachi, S. Toda, M. Tomura, K. Ito and T. Ikawa, "Reflection Imaging of the Crust and the Lithospheric Mantle in the Lützow-Holm Complex, Eastern Dronning Maud Land, Antarctica, Derived from the SEAL Transects," Tectonophysics, Vol. 508, No. 1-4, 2011, pp. 73-84.

doi:10.1016/j.tecto.2010.08.005

[25] T. Isse and I. Nakanishi, "Inner-Core Anisotropy beneath Australia and Differential Rotation," Geophysical Journal International, Vol. 151, No. 1, 2001, pp. 255-263. doi:10.1046/j.1365-246X.2002.01780.x

[26] G. Toyokuni, H. Takenaka, M. Kanao, D. A. Wiens and A. A. Nyblade, "Comparison of Global Synthetic Seismograms Calculated Using the Spherical 2.5-D FiniteDifference Method with Observed Long-Period Waveforms including Data from the Intra-Antarctic Region," Polar Science, Vol. 6, No. 2, 2012, pp. 155-164. doi:10.1016/j.polar.2012.06.001 